\title{
Embedded Based Compact Fuzzy System to Speed Control of Single Phase Induction Motor
}

\author{
Priyanka Kumbhar, Dr.S.D.Lokhande \\ ${ }^{I} P G$. Student of, Sinhagad college of engineering,Pune. \\ ${ }^{2}$ Principal-SCOE, Pune
}

\begin{abstract}
In this paper fuzzy logic techniques is used to control the speed of a single-phase induction motor. The implementation of hardware is based on a standard ARM controller, without any additional components for the fuzzy logic controller for controlling speed of induction motor keep constant the voltage and frequency ratio of the induction motor supply source. In this speed controlling the reference speed varies from 500rpm to $1000 \mathrm{rpm}$. The response of the fuzzy controller is depending upon variation of load and speed. This fuzzy control system is built on ARM processor, which uses speed error and speed error variation to change both fundamental voltage amplitude and frequency of a sinusoidal pulse-width modulation.
\end{abstract}

Keywords: ARM processor, fuzzy control, , induction motor.

\section{Introduction}

Induction motors are mostly used in several industrial sectors. Due to simple and rugged structure this motor is frequently used for adaptation of several load situations, and low cost acquisition and maintenance. Induction motors are the most widely used motors for industrial control and automation. They are robust and reliable. When power is applied to an induction motor at its required specifications, and runs at its rated speed. But different applications need different speed operations. Speed control of Induction motor is complex due to its nonlinear characteristics. For speed control of induction motor there are two type's i.e. scalar control and vector control. For speed control system several studies have been carried out in this field, but due to low steady state error scalar speed control system shows simple structure. Therefore, the constant voltage-frequency $(\mathrm{V} / \mathrm{f})$ scalar control system is considered in this project due to its large application in industrial fields. This work is an attempt to design an Embedded Fuzzy Controller for an induction motor speed control. V/f is the most common method of speed control. This method is most suitable for high accuracy of speed control.

For many motor control applications fuzzy logic has a growing in the last few years. The Fuzzy Logic Controller operates in a knowledge-based, fuzzy-based control methodology has the ability to cope with system nonlinearity and its control performance is less affected by system parameter variations. Fuzzy logic is used because of its simplicity and effectiveness for solving control problems. Moreover, fuzzy techniques included a linguistic rule base which is designed for taking advantage of system qualitative aspects and expert knowledge. In this paper proposes an alternative method for speed control of induction motor using simple embedded based fuzzy logic algorithm, so that it can be built in hardware with reduced memory space and low computational power.

\section{V/F Speed Control System Structure}

The proposed method was applied to ARM for real-time V/f induction motor speed control using fuzzy logic algorithm. The proposed method has advantage related to the symmetrical feature of the fuzzy membership function in order to store its minimum part in a vector table. From a simple and quick indexation calculus, the entire membership function with all linguistic terms can be restored. This procedure significantly reduces the memory space required for a membership function. In this also discusses performance analysis of the proposed fuzzy-control system in relation to load-torque and reference-speed variations. The fuzzy-control algorithm was implemented into ARM The device was responsible for measuring the IM shaft angular speed with an optical encoder, achieving the fuzzy control algorithm and, finally, generating the sinusoidal-modulated PWM signal in order to turn on solid state relay (SSR) 


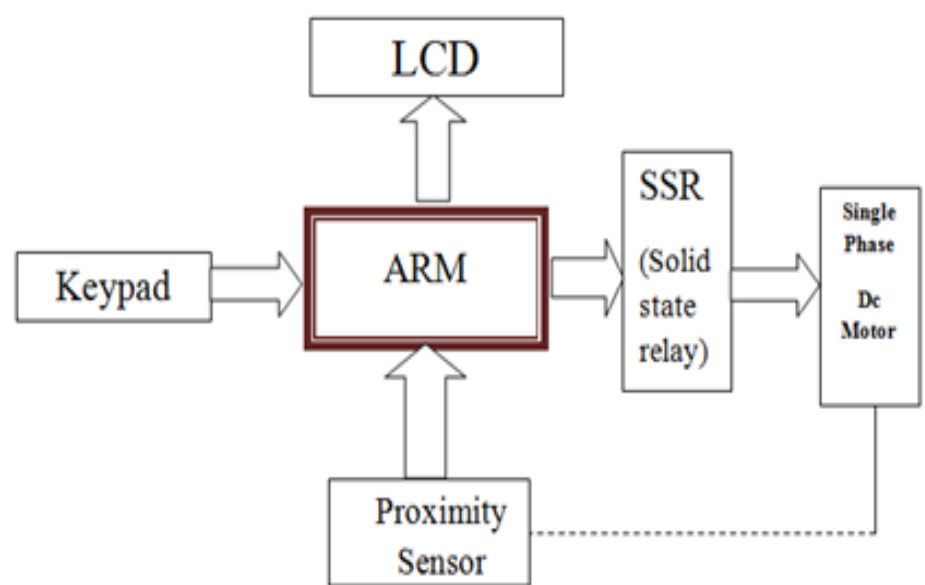

Fig2.1. Speed control system block diagram.

Keypad: Keypad is used to enter different speed of induction motor. These speeds are compared with reference speed and calculate the error difference between reference speed and entered speed.

LCD: LCD is used to display the entered speed and obtained speed.

ARM: ARM is a family of instruction set architectures in this project it is used for Embedded based processors .ARM contain a reduced instruction set (RISC) architecture. In ARM processor $32 \mathrm{~KB}$ instruction cache and 32 $\mathrm{KB}$ data cache, included and it is running at up to $208 \mathrm{MHz}$ High-performance multi-layer AHB bus system. It provides a separate bus for CPU (central processing unit) data and instruction fetch, two data buses for the DMA controller, and another for the USB controller multiple serial interfaces, including seven UARTs, two SPI controllers, and two single master I2C-bus interfaces.

Proximity Sensor: It is a one type of sensor which is used to detect the presence of nearly objects without any physical contact. When it detect object it emit an electromagnetic field or a beam of electromagnetic radiation and observe the changes in the field or return signal. Using this sensor we determine the motors running speed. This sensor is connected to ARM processor

Solid state Relay (SSR): Solid state relay is used to control the input voltage i.e.230V supply, using this SSR this $230 \mathrm{v}$ supply voltage is reduced according to our require voltage and according to that voltage motors speed should be controlled.

Single phase DC motor: The speed control of the induction motor was carried out by maintaining constant the voltage frequency ratio in order to avoid the air-gap flux variations. If the supply voltage is varied without frequency adjustment, the induction motor can operate in the flux saturation region or with a weakened field. The block diagram of the proposed fuzzy control system is illustrated in fig.2.1.

\section{Fuzzy Logic Expert System}

A fuzzy expert system is a expert system which is used for collection of fuzzy membership functions and rules, instead of using Boolean logic for processing data. This system is not based on differential-equation based controllers. These system works like human brain so that it gives better performance than conventional controllers.

Now days there are many products available in market which is controlled by fuzzy logic in which different types of fuzzy logic controller are used.fig 3.1 shows fuzzy logic expert system.

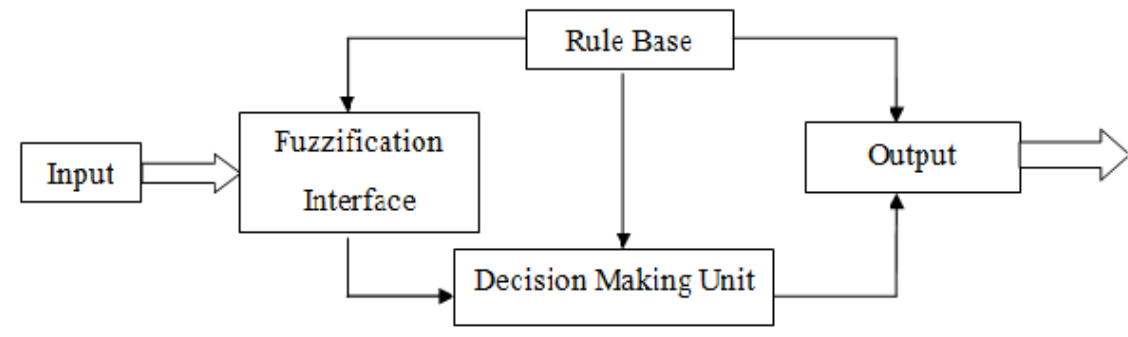

Fig.3.1 Fuzzy Logic Expert System.

Input: These are used to enter the input signal to system, the signal which is in the form of voltage and this voltage is controlled with the help of fuzzy logic controller. 
Fuzzy control is based on the fuzzy logic theory. Fuzzy controllers are rule-based controllers in this controller "if-then" format is used for control process. In this format, several variables could be used either in condition or conclusion side of the "if-then" rules. Hence due to these conditions mathematical model of the system is not required in fuzzy control, so it can be applied to nonlinear systems. The structure of expert system is shown in Figure.3.1

Fuzzification interface: In fuzzification interface different functions are involved from which $1^{\text {st }}$ is measure the value of input variables, second is scale mapping performs which include transfer the range of value of input variables into required universe of discourse and third one is performing a fuzzification function that converts input data into suitable linguistic value which may be from labels of fuzzy set.

Rule Base: fuzzy rule based system is also called fuzzy inference system; this is most important part of fuzzy logic system. A rule-based fuzzy logic system based upon IF-THEN condition. In fuzzy rule based system linguistic variables are used. This linguistic variables obtained from fuzzification interface. Rules can be solved in parallel in hardware, or sequentially in software. rule-based FLSs have been applied in many different fields and industries.

Decision making Unit: decision making unit perform inference operation on rule, it is very simple because it give appropriate solution for given input. This unit based on fuzzy set which is used in fuzzy expert system. The decision taken by this unit which is based on condition used in rule base block. According to that decision output should be obtained in this paper we control the speed of induction motor so output of this unit which is in form of voltage controlling variable.

Output: This block contain the controlled voltage which is applied to the induction motor for speed controlling of motor according to our requirement

3.1. Description of the Proposed Intelligent Controller: Proposed system divided into 5 main part i.e.LCD, ARM, SSR, single phase DC motor, keypad. In proposed control system the first input is the set point, which represents the desired speed of motor. The second input is the feedback signal, which represents the actual motor speed. FLC was applied to this system to control the speed of the induction motor. The output of FLC is sent to the solid state relay to produce waveform with variable voltage and frequency to control the speed of the induction motor The difference between desired (set point) and measured speed is the first input variable i.e. error $(\mathrm{E})$ and other input is the change of error $(\mathrm{CE})$. the change in frequency is output variable $(\mathrm{CF})$. All input and output variables were normalized to be fit in the some range. Using output variable (CF) we calculate the needed change of frequency for control the speed of induction motor. The feedback signal is the measured value of the induction motor speed while set point is the desired speed of the motor. The measured speed is multiplied by $(30 / \pi)$ to convert the $(\mathrm{rad} / \mathrm{s})$ unit into $(\mathrm{rpm})$ unit. The error signal (which is the difference between actual speed and desired speed) and its derivative are used as input for FLC. The output of FLC is the required change in frequency which will be integrated continuously, while the saturation is used to limit the output frequency within the system limitations. The control signal, which represents the frequency in this case, is sent to $\mathrm{V} / \mathrm{Hz}$ which will maintain a constant ratio between voltage and frequency to keep the torque constant while the speed varies. The output is sent to PWM generator which will accordingly produce a PWM signal that meets the input frequency. Resulted PWM signal is used to trigger the (SSR) Solid state Relay. And other side of SSR the motor is connected according to PWM signal motor speed is changed.

\section{Results And Discussion}

Different tests can be done using Fuzzy logic controller to control the speed of induction motor. Different Test should be done using various operating conditions such as reference speed and applied load. The performance of FLC were analyzed and compared. Table 4.1 shows a numerical performance of FLC in terms of rise time and settling time.

\begin{tabular}{|c|c|c|}
\hline $\begin{array}{c}\text { Reference speed } \\
(\mathrm{rpm})\end{array}$ & Rise time (s) & Settling time (s) \\
\hline 600 & 12 & 14 \\
\hline 800 & 14 & 18 \\
\hline 1000 & 13 & 16 \\
\hline 1200 & 14 & 17 \\
\hline
\end{tabular}

Table 4.1 FLC performance in speed response 
It is clear from the above table that FLC showed faster response in both rise time and settling time. FLC showed the ability to control speed of the single-phase induction motor and provide an accurate and fast response with relatively no overshoot and no steady state error.

\section{Conclusion}

The proposed embedded fuzzy system has a simplified architecture which reduces memory space requirements. Although it implies an additional computational cost, this does not compromise the practical performance in a V/f control system. From the above discussion it concludes that we can control the speed of the Induction motor using fuzzy controller. The fuzzy controller will give the better performance compared to other controllers.

\section{References}

[1]. Marcelo Suetake, Ivan N. da Silva, Member, IEEE, and Alessandro Goedtel "Embedded DSP-Based Compact Fuzzy System and Its Application for Induction-Motor V/f Speed Control" ieee transactions on industrial electronics, vol. 58, no. 3, march 2011.

[2]. F. Zidani, D. Diallo, M. E. H. Benbouzid, and R. N. Saï, "A fuzzy-based approach for the diagnosis of fault modes in a voltage-fed PWM inverter induction motor drive," IEEE Trans. Ind. Electron., vol. 55, no. 2, pp. 586-593, Feb. 2008

[3]. M. N. Uddin, Z. R. Huang, and M. I. Chy, "A simplified self-tuned neuro fuzzy controller based speed control of an induction motor drive," in Proc. IEEE Power Eng. Soc. Gen. Meet., 2007, pp. 1-8.

[4]. E. Bim, "Fuzzy optimization for rotor constant identification of an indirect FOC induction motor drive," IEEE Trans. Ind. Electron., vol. 48, no. 6, pp. 1293-1295, Dec. 2001.

[5]. Zadeh L.A., "Fuzzy sets," Information and Control, Vol. 8, p.p. 338-353, 1965.

[6]. Mendel J.M., "Fuzzy Logic Systems for Engineering: A tutorial," Proceedings of the IEEE, Vol. 83, pp. 345-377, 1995

[7]. Arkhipov M., Krueger E., Kurtener D., "Evaluation of Ecological Conditions Using Bioindicators: Application of Fuzzy Modeling" International Conference on Computational Science and its applications - ICCSA 2008, Part I, LNCS 5072, pp. 491-500, 2008

[8]. Li H., Guota M. M. (ed.), Fuzzy logic and intelligent systems, Kluwer Academic Publishers, USA, 1995.

[9]. Rashid M. H. (ed.), Power electronics handbook: devices, circuits, and applications, Academic Press, USA, 2007

[10]. Arunapriya.P "Implementation of Embedded based Fuzzy system for Induction motor V/f speed control” International Journal of Scientific \& Engineering Research, Volume 3, Issue 6, June-2012.

[11]. Sreenivasa Rao Jalluri, Dr. B. V. Sanker Ram, A neuro fuzzy controller for induction machines drives Journal of Thoretical and Applied Information Technology.

[12]. A. Goedtel, I. N. da Silva and P. J. A. Serni, —Load torque identification in induction motor using neural networks technique $\|$, Electric Power Systems Research, vol. 77, no. 1, pp. 35-45, 2007.

[13]. A. I. Al-Odienat and A. A. Al-Lawama, -The advantages of PID fuzzy controllers over the conventional types\|, American Journal of Applied Sciences, vol. 5, no. 6, pp. 653-658, 2008.

[14]. A. Tae-Chon, K. Yang-Won, H. Hyung-Soo and W. Pedricz, -Design of neuro-fuzzy controller on DSP for real-time control of induction motors\|, Proceedings of IFSA World ongress and 20th NAFIPS International Conference, vol. 5, pp. 3038-3043, 2001.

[15]. Bin Lu, Thomas G. Habetler, and Ronald G. Harley" A Survey of Efficiency-Estimation Methods for In-Service Induction Motors" IEEE TRANSACTIONS ON INDUSTRY APPLICATIONS, VOL. 42, NO. 4, JULY/AUGUST 2006. 